NEUROLOGICAL PICTURE

\title{
Cervical subdural haematoma
}

A 70 year old man with a history of polycythaemia rubra vera suddenly developed neck and shoulder pain and began to lose power first in his arms and then his legs over the next 2 hours. Neurological examination showed profound weakness in all limb muscles, absent tendon reflexes, and a sensory level at $\mathrm{C} 4$. There were no cranial nerve abnormalities. Initial head CT (figure A) showed an abnormal compressive mass at the level of the foramen magnum. Sagittal T1 weighted brain MRI (figure B) showed a circumferential mass extending from the clivus to the foramen magnum and upper cervical cord (arrow). His breathing became laboured and he was intubated, ventilated, and taken to the operating theatre, where at operation a cervical subdural haematoma was evacuated. No obvious bleeding source was identified. No recovery was made post-operatively and he died 2 days later.

Cervical subdural haematomas are rare and usually have an underlying cause. ${ }^{1}$ Abnormal platelet function, thought to underlie the bleeding tendency seen in polycythaemia rubra vera, ${ }^{2}$ could have been responsible for the haematoma in this case, although he had been asymptomatic off treatment for 4 years with normal platelet count and packed red cell volume during this time.

Cervical haematoma should be suspected in all patients with sudden onset neck and upper limb radicular pain with signs of cord compression, and urgent imaging is useful in delineating potentially treatable patients.

PAUL MADDISON

Department of Clinical Neurology, Leeds General Infirmary, Great George Street, Leeds LS1 3EX, UK email paul@piglet2.demon.co.uk 1 Langmayr JJ, Ortler M, Dessl A, et al. Management of spontaneous
extramedullary spinal haematomas: results in eight patients after MRI
diagnosis and surgical decompression. $\mathcal{F}$ Neurol Neurosurg Psychiatry
1995;59:442-7.
2 Kalina P, Drehobl KE, Black K, et al. Spinal cord compression by spontane-
ous spinal subdural haematoma in polycythemia vera. Postgrad Med $\mathcal{f} 1995$;
$71: 378-9$.
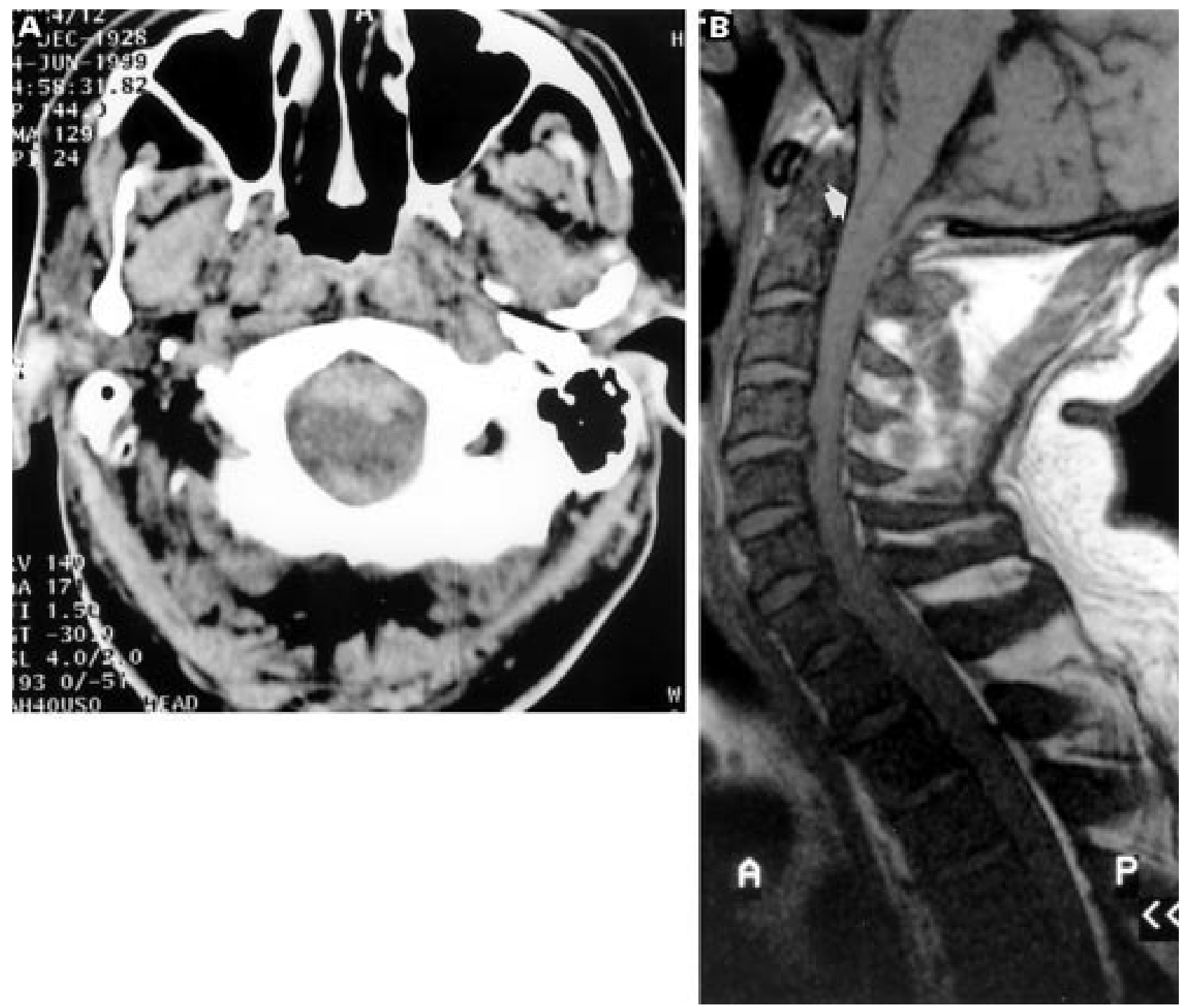